\title{
中国語の「ネット語」と日本語の「若者ことば」における造語法の比較研究 A Comparative Study of Word-Making in Chinese Internet Language and Spoken Japanese among the Youth
}

\section{王 崗/方 韻 深圳大学/香港中文大学}

\section{要旨}

インターネットの普及につれ、中国のネット上、新語がたくさん作られている。 「被就業」（就職だとされる）、「水帖」（ゴミレス）などがそうである。これらの ネット語を見渡すと、その多くが中国の若者たちによって創造され、使用されること がわかる。さらに、その一部が広く認知され、普通の人たちにも使用されるようにな っている。

一方、日本語には、「コビる」、「酷い」のように、若者が中心で使用される言 語形式があるが、それは普通「若者ことば」だと言われる。

いずれも若者たちによって作られているものであるが、中国語のネット語と日本 語の若者ことばとの間に、造語法において興味深い類似点と相違点が観察できる。例 えば、両者のいずれにも字母からなる新語、品詞の転成による新語などがあるが、日 本語に「人名十る」という特徴的な造語法があるのに対して、中国語において名詞そ のままで動詞に転成するなど独自の造語法が見られる。

キーワード :

ネット語、若者ことば、造語法、新語 


\section{中国語の「ネット語」と日本語の「若者ことば」における造語法の比較研究}

\section{王 崗/方 韻 \\ 深圳大学/香港中文大学}

\section{1. 前言}

随着互联网的普及, 中国的网络上出现了大量的新词新语, 如 “被就业”、“水 帖” 等。这些网络词语一般统称为 “网络词”。这些词语一般多是由中国的年轻人所创 造使用的; 但其中也有部分词语广为人知后, 从网络语言进入到普通人的日常口语中, 如 “月光族”、“裸考” 等。

再来看日语, 我们会发现日语中也有一种以日本年轻人为主要使用群的语言形式, 如“コビる”、“酷い”等，它们一般统称为 “青少年俗语”（即 “若者ことば”）”。 而且, 这些俗语词中也有一部分被普通的日本人所接受并进而普及开来, 从而变成了普 通的口语词汇，如 “マジ（で）”等。

虽然汉语与日语的语言类型、语法和词汇的表现形式等有很大不同, 但中日两国 年轻人所创造的一些新词语或新用法, 却让我们认识到词语生成的一些共有规律, 同时 还能近距离观察到语言类型的不同对新造词的影响作用。以下, 本文就从造词法出发来 探讨这些有趣的话题。

\section{2. 何为造词法?}

造词法, 顾名思义就是创造新词的方法。人们在造词时, 可以根据本民族的语言习 惯, 掌握和运用现有的语言材料组成各种各样的新词。在组成新词的过程中, 人们使用 的方法是多种多样的, 这些为事物命名创制新词的方法, 就成为造词法 (葛本仪, 2014:69）。

另外, 关于造词法的类型, 葛本仪（2014）总结出了 “音义任意结合法、摹声 法、音变法、简缩法” 等 8 种。本文结合野村雅昭（1977）、贺国伟（2003）、葛本 仪（2014）等的分析，仅就汉语 “网络词”（以下简称 “网络词”）与日语 “青少年 俗语”（以下简称 “青少年俗语”) 中较有特色的下述几种造词法进行考察：
(a) 省略法
（b）旧词新用法
(c) 仿拟法

1 “若者ことば”一般指口语形式, 但其中已经有相当部分进入到网络世界里, 同时日语网络上也有 年轻人之间通行的网络俗语，因此本文的探讨范围虽然以口语形式为主，但也兼顾网络部分。 


\section{3. 省略法}

词语创造上常见的一种方法就是省略，这一点无论是汉语还是日语都是一样的; 只是具体到汉语 “网络词” 与日语 “青少年俗语” , 它们却有着不同于传统造词法的一 面。

\section{1 字母词}

汉语和日语中都能见到一些字母缩略词语，如 “WHO” ( World Health Organization, 世界卫生组织）、“MBA” ( Master of Business Administration, 工商管 理硕士）、“CCTV”（ China Central Television, 中国中央电视台）、“NTT” （Nippon Telegraph and Telephone Corporation, 日本电信电话公司）等。这些字母词一 般是为了方便表达音节较多的专有或特定名词来使用的。但在 “网络词” 和 “青少年俗 语”里字母词有时却呈现出另一番情景。

先看汉语的部分。在汉语的网络上, 年轻人因标新立异、搞笑、隐晦、时尚等心 理需要, 会将短语或短句的汉语拼音的首字母大写进而合成字母词, 如 “LX”、 “GX”、“FRJJ” 等。单看这些字母词, 会让圈外的人士不明所以, 但将它们还原之 后，就会自然明白。如 “LX” 是 “Lou X Xia”（楼下，论坛中指本帖之后的回帖）、

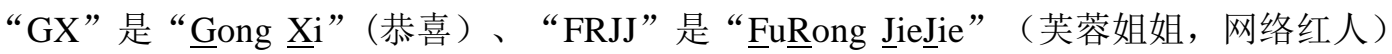
的首字母合写。这可以说中国网络青年的一个崭新的造词创意, 因为迄今为止在汉语的 造词法中还鲜有这样的现象, 但在网络这个平台上它却大行其道, 并且还形成了一个庞 大的字母词汇群。

而日语也是这样。日本的年轻人运用日语文字的罗马字拼写方式, 将各相关词句 的首字母摘出、合并进而创造了大量的字母词汇。如 “DD” (Daredemo Daisuki=だれ でも大好き，谁都喜欢）、“KY”（Kuki ga Yomenai=空気が読めない，不识趣） 等。这种方式在此前的日语里比较少见，但在 “青少年俗语” 中却屡见不鲜。

传统的字母词通常是专有名词、并且多是外语词语的缩写而成, 如前文的 “WHO”、“NTT” 所见; 而 “网络词”与 “青少年俗语” 中的字母词有别于传统造词 法的是, 它们可以较为随意地用字母拼写、省略、合成任何词语、短语或短句, 以此来 增加圈内同好、朋友之间的交际之需。而随着欧美日文化的影响, 汉语的 “网络词” 中 还有大量来自英语或日语的字母词出现, 如 “FTBOMH” ( from the bottom of my heart, 发自内心的）, “Ninja”（ninja=忍者, 电脑游戏中不守规矩的玩家）, 这是现 今日语 “青少年俗语” 所不多见的现象。 


\section{2 缩略词}

除了上述字母词外, 缩略词也是一种省略而成的词语形式。顾名思义, 缩略词是 词语的紧缩形式, 是在原有词语的形式上, 按照词义选取词语的代表字简化、合并而 成。这种造词法在普通汉语和日语里比较常见。如汉语的 “冬奥会” 是 “冬季奥林匹克 运动会” 的缩写, “国务院扶贫办” 是 “国务院扶贫开发领导小组办公室” 的缩写; 语的 “日協連” ( “日本生活協同組合連合会”) 、“朝鮮総連” ( “在日本朝鮮人総 連合会”) 等也是这样。

回过头来看 “网络词” 和 “青少年俗语” , 却发现其中的缩略词竟然有着另一种 表现。先看汉语的部分。检索汉语的 “网络词”, 我们发现除了一般常见的缩略词外, 中国的网络青年还新造了这样的词语：老板（“老是板着脸”的缩写）、可爱（“可怜 没人爱” 的缩写）、脱光 ( “脱离光棍” (脱离单身) 的缩写)。这样的缩略词不同于 传统的是, 它们不仅是将短语或短句缩写, 同时还采用了双关语的修辞手法。再如 “姜 一军” ( “生姜价格疯狂上涨、超出合理范围” 的戏谑说法) , 字面上看似乎象人名, 但实际上它是 “姜你军” 的谐音, “姜你军” 则源自 “将你军” , 而 “将你军” 又是象 棋用语 “将你一军” 的缩略说法。所以, 汉语 “网络词” 不同于传统, 它常常会伴有一 些奇异、调㑆、搞笑等的语义色彩。

无独有偶, 日语 “青少年俗语” 中的一些缩略词也有异曲同工之妙, 如 “ノリ 男”，字面上看它似乎是 “紫菜男”之类的意思，实际上该词是 “（テンションが高く て）ノリがいい男” 的缩略词, 是省略加双关而形成的一个词语。此外, 如 “厨房” 在 日语 “青少年俗语” 中并非 “烹饪场所” 之意, 而是 “小中学生” （此处的 “小” 意为 “不起眼” ) 的意思。它的成词机理是先将 “中学生坊や” 缩写成 “中坊”、再进一步 谐音成 “厨房”, 这实际上是省略加谐音而成的缩略词。“鯖缶” 也是这样, 从字面上 看似乎是 “青花鱼罐头” 的意思, 实际上它是 “共バ管” 的谐音替代词, 而 “紊管” 是 “サーバ管理者” 的缩略词。

总而言之, 无论是 “网络词” 还是 “青少年俗语” , 在缩略这个造词法上有着 极为相似的一面。之所以如此, 是因为中国和日本的年轻人都喜欢特立独行, 这使他 们更愿意追求表达效果的 “新奇特” ( “新鲜、奇异、特别”) , 所以在语言运用上 他们会采用省略、双关、谐音、借代、合成等多种组合方式创造属于自己的特色词 汇, 同时这也是上述 “网络词” 和 “青少年俗语” 在缩略词的造词法上不同于传统的 一个最大诱因。 


\section{4. 旧词新用法}

造词法中还有一种形式叫 “旧词新用” , 就是通过扩展既有词语的用法、语义来 丰富、突出词语的表达功能。其中词类（词性）转换、活用便是一个常见的手法 ${ }^{2}$ 。

汉语和日语都有词类转化和活用的现象, 如名词转动词、形容词转副词、名词转 词缀等。汉语的词类没有形态作为外在标志, 就常常要通过句法来显示, 所以词类转换 “是汉语语法的一大特点” (史存直, 1989：43）。如以 “帮助” 为例, 在 “帮助他 人” 的句式中它是动词, 在 “他人的帮助” 的句式中就成了名词。除此之外, 词义演变 和词语借用也造就了汉语较多的词类转换和活用现象, 如 “子” 在 “杯子” 中是词缀, 而实际上它脱胎于 “莲子” 的 “子” 等实意名词。从这些地方来看, 可以说汉语是词类 转换和生成较为发达的语言。

日语也有词类转换的现象, 只是因为日语有词形变化, 使得部分词语完全可以不 通过句法来实现词类的转换。如以 “運動” 为例, 在这个词形下它是名词, 但在其后添 加动词词素 “する” 则变为动词 “運動する” ; 再如 “美しい”, 它本是形容词, 但词 尾 “い”去掉后再添加后缀 “さ”, 就衍生出了名词 “美しさ”。日语的这种造词法是 汉语所不具备的。

由此可见, 虽然具体表现相异, 但在汉语和日语里词类转换和派生等都是一种比 较常见的造词法; 然而, 在 “网络词” 和 “青少年俗语” 中, 这种方法却有了新的表象 特征。

我们先来看看汉语的 “网络词”。“秒” 作为普通汉语词汇来说是个纯粹的名 词, 但作为 “网络词”, 它却是作为动词来使用的, 如 “秒了一堆便宜货” 这句话所 示。那缘何该词会由名词转为动词的呢? 实际上, 它的这个转换经历了一个接受、创新 的过程：先是吸收自日本格斗界术语 “秒殺”, 之后被中国的年轻网民借用为动词, 词 义相应变为 “网游中迅即杀死对方或被对方所杀” 和 “低价抢购” ，之后进一步缩写为 “秒”, 由此一个纯粹的名词就成为了动词。再如 “被” 这个表被动之意的词语。它原 本是用于名词前的介词或用于动词前的助词, 但经大学生网民所发的一个 “被就业” （被莫名签署了就业协议）的帖子开始, 迅速为其他网民所效仿, 进而类推成 “被结 婚、被网民、被增长、被福利” 等诸多词语, 这其中的 “被” 原本作为被动句语法形式 的功能和语义均已弱化, 更多的是为中心词的语义添加来服务。

接下来看看日语的“青少年俗语”。“マジ”这个词源自“まじめ”，词形虽有 省略, 但词类并没有发生改变, 仍是形容动词（“な形容詞”)，这从 “マジな話” 的 说法中即可看出。但在观察“マジ切れ、マジネタ、マジむかっ、マジいや、マジボケ、

2 这一节的探讨不考虑词源的问题, 只将焦点集中在词语的实际使用情况上。 
マジキチ” 等诸多关联词例时, 我们会发现其中的 “マジ” 语义已经弱化, 功能上也只 是对后项中心词的程度和语义进行强调而已。从这两点来看, 其中的 “マジ” 完全具备 了一般词缀的构词和表达功能, 所以说它由形容动词转换为（类）前缀词似无不可。

“与謝野る”是另一个旧词新用的典型。日本近代有一位著名的浪漫派女诗人叫与 谢野晶子, 她曾经出版过一部著名诗集《みだれ髪》。于是日本的年轻人忽发奇想, 就 形容某人头发乱糟糟为 “与謝野る”。人名后直接加上动词的构词词素 “る” 合成动词, 在日语的词汇史上似不多见, 但日本的年轻人却能这样造词。除了 “与謝野る” 外, 近 年还出现了 “枝る”（工作狂, 源自原民主党执政时期官房长官枝野幸男处理福岛核泄 漏时的工作干劲）。类似成词机理（名词十る）产生的其它词语还有 “アサヒる”、 “街る”、“化粧る”、“コビる”等。

前文已述, 词类转换、活用和兼类的现象在汉语和日语里并不稀奇, 但通过上面 的分析可以看出: 中国和日本的青少年会用一些意想不到的造词手法来进行不同于一般 情况的词类转换, 这是青少年亚文化在造词法上的一个特色; 只是日语部分有时可通过 “名词 + る 等变形方式转换, 而汉语不是通过变形而是通过句式应用来显示词类转换, 这是两者明显的一个差别。

\section{5. 仿拟法}

仿拟是造词法, 同时也是一种修辞方式, 主要是指 “对现成的固定词组、句子、 篇章甚至语体临时加以仿造” (杨绪明, 2014:246)。仿拟是汉语和日语造词法中较 为常用的方法。如以汉语的 “热” 为例, 在表示 “某种热潮” 这个词典义项下, 先后仿 拟出了 “出国热、办学热、国学热、汉语热、集邮热、美容热” 等大量新词语或新说 法。日语也是一样。如以后缀的 “族” 为例, 自 “斜陽族” 开始, 先后仿拟出现了 “太 陽族、空際族、社用族、原宿族、団地族、ながら族、暴走族” 等一系列新词。所以, 仿拟对汉语和日语的新词生成起到了很大的推动作用, 这一点当然也体现到 “网络词” 和 “青少年俗语” 中, 只是其中的年轻人特色有时也很明显。

首先谈的是汉语的 “网络词”。汉语的词缀 “族” 引申指人的说法据说源自日 语、经台湾地区传播进而传入内地并广泛流行开的（李晓东，2003；王晟，2007）。 据李晓东 (2003) 的分析, 自 1947 年开始, 在日语中就已经存在着几十个 “族” 词 语。而近年来, 随着中日交流的增加以及日本文化的影响, 汉语从日语中借入了部分 “族” 词语, 国内的年轻人也在这些借入词的基础上仿拟出许多 “族” 词缀的网络词, 如 “奔奔族、蚁族、辣奢族、库索族、啃椅族、波波族、阿鲁族、长草族” 等。再如国 内的年轻网友根据知名学者易中天的 “悲剧” 一说仿拟出了 “杯具、洗具、餐具” 等新 词。所有这些网络仿拟词, 我们可以发现一个共同点, 是它们几乎无法从字面猜出各词 
的词义来。这一点是网络上很多仿拟词的一个特色。因为网络仿拟词的形成不仅运用了 仿拟的手段, 有时还会将比拟、摹状、谐音、借代等多种手法融入其中, 这使得 “网络 词” 中的仿拟词常会令人扑朔迷离、不解其义, 这也是它与上文 “热” 字系列为代表的 普通仿拟词之间的最大区别。

那么, 日语的 “青少年俗语” 又如何呢? 试看两例。一般意义上形容词在日语里 分为形容词和形容动词。但日本的年轻人根据仿拟的原理创造出的形容词倾向简单化, 即在很多词语后添加形容词的构词词素 “い” 来合成新式形容词, 如 “ダボい” 是象声 词 “だぼだぼ” 省略后添加 “い”而成, “雑い（雑だ）、酷い(酷だ)” 则是将形容 动词词尾 “だ” 改为 “い” 合成的, “プロい、雑魚い、エゴい” 则是名词后添加 “い” 而成的; 还有直接将形容动词及其类似助动词仿拟成形容词的例子, 如 “きれ< ない（きれいだ）、〜みたく（〜みたいだ）、すきくない（すきだ）”等。再如 “す ごい” 原本是形容词, 但日本的年轻人已经习惯将它作为准副词来使用, 于是就出现了 “すごいおいしい”、“すごいむかつく”等一系列说法, 并由此还仿拟出 “やばい寒 い”、“えらいしゃべりまくってた”3等类似的形容词作准副词的用法。

因为日语的用言具有形态标志, 所以 “青少年俗语” 中的这部分仿拟词有时会通 过活用变形来操作, 这点就与 “网络词” 有很大的不同; 另外, 日语有形容词和形容动 词这两种表事物性质和状态的词类, 而在 “青少年俗语” 中形容动词有时却能被简单地 仿拟成形容词, 这也是汉语 “网络词” 所见不到的现象。但不管怎样说, “网络词” 和 “青少年俗语” 在仿拟词上所追求的奇异性、趣味性及其能产性却是殊途同归。

\section{6. 结束语}

本文从造词法的角度探讨了汉语 “网络词” 和日语 “青少年俗语” 中的一些有趣 现象。从中我们可以看出, 无论是汉语的 “网络词” 还是日语的 “青少年俗语” , 在造 词法上都追求着 “新奇特” (即 “新鲜、奇异、特别” ) - - 汉语 “网络词” 涌现了 “GX” 、动词 “秒” 等词语; 日语 “青少年俗语” 则出现了 “KY”、“プロい” 等词 语。造词法还是一般的造词法, 但经年轻人之手创造出的词语或用法却常常迥异于普通 汉语和日语的既有形式, 这是 “网络词” 和 “青少年俗语” 不同于传统语言形式的地 方。

从形式、用法和语义表达上来看, “网络词” 和 “青少年俗语” 常常令人匪夷所 思, 并引起人们对语言传统和纯洁性的担忧。这些地方确实需要我们认真对待和思考, 但作为一种客观真实存在的语言现象, 完全一味的抨击和抹杀并不能解决问题。因为词

3 “すごい” 等的副词性用法也可以说是 “旧词新用法” 的一个例子, 但在这里主要想强调的是 “や ばい”、“えらい”的这类新用法均由 “すごい”的上述用法仿拟而成。 
语的形成和定型往往是去伪存真、拨乱反正后的一个沉淀结果, 所以我们要相信语言的 自净能力; 同时深入这些混沌、纷乱的词语世界, 可以让我们近距离观察和发现词语的 生成规律, 从而为我们认识、接纳、理解新词提供一些理论支撑。

\section{附记}

本文的完成得到了日本住友财团 “2013 年度亚洲各国日本相关研究资助计划”（课题编号: $138011 ）$ 的资助；同时在此也感谢审阅老师给予本文的中肯建议和批评指正。

\section{词例出处}

・王崗・方韻（2015）「若者ことばの文法性と非文法性の表現」『日本学刊』第 18 号、香港日本 語教育研究会

• 汪否（2012）『新华网络语言词典』北京：商务印书馆

- 北原保雄（監修）、「もっと明鏡」委員会（編集）（2006）『みんなで国語辞典！これも、日本 語』東京 : 大修館書店

・渋谷語制作委員会（2008）『渋谷語事典 2008』東京：トランスワールドジャパン

・张玉玲 (2014) 『网络语言的语体学研究』北京: 中国社会科学出版社

・汤玫英（2010）『网络语言新探』郑州: 河南人民出版社

·方韵・小出雅生（2011）『时尚日语』合肥：中国科学技术大学出版社

・http://www.yahoo.co.jp/ (2015 年 9 月-10 月汶览)

・ netyougo.com/tag/ネットスラング (2015 年 9 月-10 月汶览)

\section{参考文献}

王晟（2007）『流行新词语』北京: 金盾出版社

贺国伟（2003）『汉语词语的产生与定型』上海：辞书出版社

葛本仪（2014）『现代汉语词汇学（第 3 版）』北京：商务印书馆

史存直（1989）『语法新编』上海：华东师范大学出版社

野村雅昭（1977）「造語法」『岩波講座 日本語 9 語彙と意味』東京: 岩波書店

杨绪明（2014）『当代汉语新词族研究』北京: 中国社会科学出版社

李晓东（2003）「日语流行语中的 “族”」『日语知识』（9）大连外国语学院 